\title{
Correction to: Epidemiology and evolution of Middle East respiratory syndrome coronavirus, 2012-2020
}

\author{
An-Ran Zhang 1,2,3, Wen-Qiang Shi ${ }^{2}$, Kun Liu' ${ }^{4}$, Xin-Lou Li ${ }^{5}$, Ming-Jin Liü ${ }^{3}$, Wen-Hui Zhang ${ }^{2}$, Guo-Ping Zhao ${ }^{6}$,
} Jin-Jin Chen ${ }^{2}$, Xiao-Ai Zhang ${ }^{2}$, Dong Miao ${ }^{2}$, Wei Ma ${ }^{1^{*}}$, Wei Liu ${ }^{2^{*}}$, Yang Yang ${ }^{3^{*}}$ and Li-Qun Fang ${ }^{2^{*}}$ (D)

\section{Correction to: Infect Dis Poverty (2021) 10:66} https://doi.org/10.1186/s40249-021-00853-0

Following publication of the original article [1], it was found that the figure 1 is incorrect. The correct figure 1
(Fig. 1) is provided in this erratum.

The original paper has been updated.

The original article can be found online at https://doi.org/10.1186/s40249-

021-00853-0.

*Correspondence: weima@sdu.edu.cn; Iwbime@163.com; yangyang@uf.edu; fang_lq@163.com

1 Department of Epidemiology, School of Public Health, Cheeloo College of Medicine, Shandong University, 44 West Wenhua Road, Jinan, People's Republic of China

${ }^{2}$ State Key Laboratory of Pathogen and Biosecurity, Beijing Institute of Microbiology and Epidemiology, 20 Dong-Da Street, Fengtai District, Beijing 100071, People's Republic of China

${ }^{3}$ Department of Biostatistics, College of Public Health and Health

Professions, and Emerging Pathogens Institute, University of Florida, Gainesville, FL, USA

Full list of author information is available at the end of the article

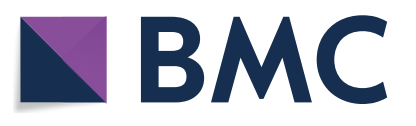

(s) 2021. Open Access This article is licensed under a Creative Commons Attribution 4.0 International License, which permits use, sharing, adaptation, distribution and reproduction in any medium or format, as long as you give appropriate credit to the original author(s) and the source, provide a link to the Creative Commons licence, and indicate if changes were made. The images or other third party material in this article are included in the article's Creative Commons licence, unless indicated otherwise in a credit line to the material. If material is not included in the article's Creative Commons licence and your intended use is not permitted by statutory regulation or exceeds the permitted use, you will need to obtain permission directly from the copyright holder. To view a copy of this licence, visit http://creativecommons.org/licenses/by/4.0/. The Creative Commons Public Domain Dedication waiver (http://creativecommons.org/publicdomain/zero/1.0/) applies to the data made available in this article, unless otherwise stated in a credit line to the data. 


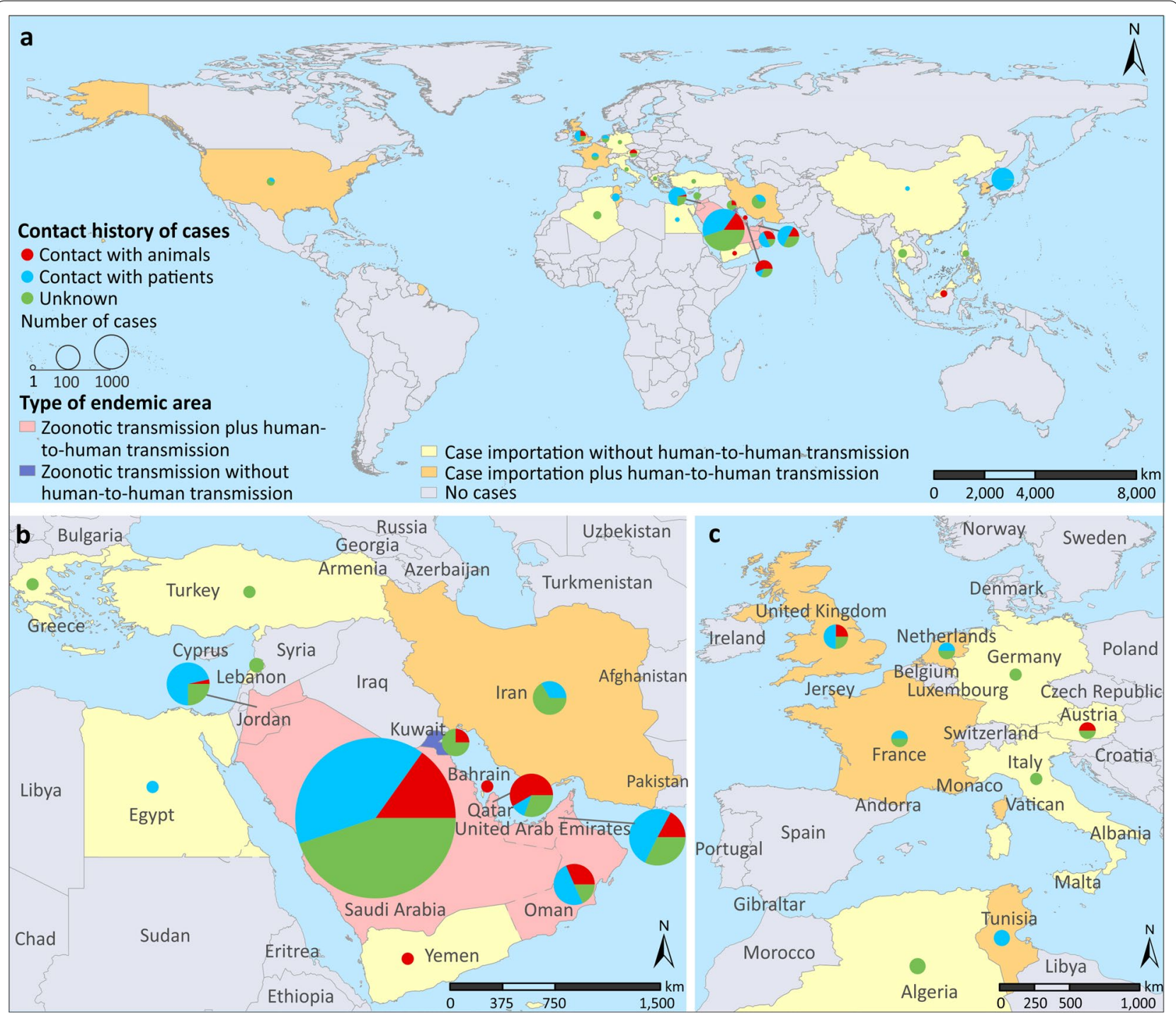

Fig. 1 Distribution of human MERS cases in the world $\mathbf{a}$, in the Middle East $\mathbf{b}$ and in Europe $\mathbf{c}$ during 2012-2020. Countries were colored according to the dominant transmission type: (i) zoonotic transmission plus human-to-human transmission, (ii) zoonotic transmission without human-to-human transmission, (iii) imported infection plus human-to-human transmission, and (iv) imported infection without human-to-human transmission

\section{Author details}

${ }^{1}$ Department of Epidemiology, School of Public Health, Cheeloo College of Medicine, Shandong University, 44 West Wenhua Road, Jinan, People's Republic of China. ${ }^{2}$ State Key Laboratory of Pathogen and Biosecurity, Beijing Institute of Microbiology and Epidemiology, 20 Dong-Da Street, Fengtai District, Beijing 100071, People's Republic of China. ${ }^{3}$ Department of Biostatistics, College of Public Health and Health Professions, and Emerging Pathogens Institute, University of Florida, Gainesville, FL, USA. ${ }^{4}$ Department of Epidemiology, Ministry of Education Key Lab of Hazard Assessment and Control in Special Operational Environment, School of Public Health, Air Force Medical University, Xi'an, People's Republic of China. ${ }^{5}$ Department of Medical Research, Key Laboratory of Environmental Sense Organ Stress and Health of the Ministry of Environmental Protection, PLA Stragetic Support Force Characteristic Medical Center, Beijing, People's Republic of China. ${ }^{6}$ Logistics College of Chinese People's Armed Police Forces, Tianjin, People's Republic of China.
Published online: 06 September 2021

\section{Reference}

1. Zhang AR, Shi WQ, Liu K, Li XL, Liu MJ, Zhang WH, Zhao GP, Chen JJ, Zhang XA, Miao D, Ma W, Liu W, Yang Y, Fang LQ. Epidemiology and evolution of Middle East respiratory syndrome coronavirus, 2012-2020. Infect Dis Poverty. 2021;10:66. https://doi.org/10.1186/s40249-021-00853-0. 